\title{
Animal-mounted gyroscope/accelerometer/magnetometer: in situ measurement of the movement performance of fast-start behaviour in fish
}

\author{
Takuji Noda ${ }^{\mathrm{a}, *}$, Yuuki Kawabata ${ }^{\mathrm{b}}$, Nobuaki Arai ${ }^{\mathrm{c}}$, Hiromichi Mitamura ${ }^{\mathrm{a}}$, \\ Shun Watanabe ${ }^{b}$ \\ ${ }^{a}$ Graduate School of Informatics, Kyoto University, Yoshidahonmachi, Kyoto, 606-8501, \\ Japan \\ ${ }^{b}$ Institute for East China Sea Research, Nagasaki University, 1551-7, Tairamachi, \\ Nagasaki, 851-2213, Japan \\ ${ }^{c}$ Field Science Education and Research Center, Kyoto University, Yoshidahonmachi, \\ Kyoto, 606-8502, Japan
}

\begin{abstract}
A novel data logger incorporating a 3-axis gyroscope, a 3-axis accelerometer, and a 3-axis magnetometer was developed and externally attached to Japanese amberjacks, Seriola quinqueradiata, to investigate the possibility of using this device for monitoring the movement performance of the faststart behaviour of fish in the field. Triggered escape behaviours were measured simultaneously by the data logger $(500 \mathrm{~Hz})$ and a high-speed camera $(200 \mathrm{~Hz})$ in a tank. By using a gyroscope, the data logger accurately reconstructed the gravity-based acceleration, 3-dimensional attitude, dynamic acceleration, and angular velocity of fish during the fast-start movement, which was impossible by previous methods using only an accelerometer and a magnetometer; these variables can therefore be used to assess the distance-
\end{abstract}

*Email: noda@bre.soc.i.kyoto-u.ac.jp, Phone: +81-75-753-3137

Preprint submitted to Journal of Experimental Marine Biology and Ecology October 29, 2013

C) 2013. This manuscript version is made available under the Elsevier user license http://www.elsevier.com/open-access/userlicense/1.0九 
related performance and manoeuvrability of fish. The escape movements can be categorised into two mechanical types (single- and double-bend) using the obtained locomotor variables, which showed significant differences between movement types. These results indicate the possibility of using this animalmounted data logger to quantify the movement performance of the fast-start behaviour of fish in nature.

Keywords: data logger, gyroscope, accelerometer, magnetometer, fast-start, fish

\section{Introduction}

The ability to move with a sudden acceleration/velocity and a rapid turning rate is important for many animals in a predator-prey context (Domenici and Blake, 1997; Higham, 2007). Kinematics and movement performance, especially those of fast-start movements in fish, have received a significant amount of attention and are usually investigated in laboratory-based settings through the use of high-speed cameras (Harper and Blake, 1990; Domenici and Blake, 1991; Hale, 2002; Lefrançois and Domenici, 2006). These studies have identified various types of fast-start behaviours [C- and S-start (Hale, 2002), including single- and double-bend responses (Domenici and Blake, 1991; Kasapi et al., 1993; Jing et al., 2004; Lefrançois et al., 2005; Jing et al., 2005), and slow and fast responses (Domenici et al., 2004)]. However, only a small number of research approaches have investigated the movement performance of fast-start behaviour of fish in their natural environment. In situ measurement of the movement performance of fast-start behaviour should reveal important insights into the physiological adaptations of animals to 
different environments and their survival strategies in complex natural habitats. This will in turn lead to an improved understanding of the relationship between movement performance and fitness (Irschick, 2003; Higham, 2007).

Bio-logging methods, which utilise animal-mounted data loggers, have been used effectively to measure the locomotion of animals in the field (Cooke et al., 2004; Rutz and Hays, 2009). In particular, data loggers including a 3 -axis accelerometer and, in some cases, a 3-axis magnetometer have been used to monitor the attitude (pitch, roll, and yaw) and dynamic acceleration of aquatic animals (Davis et al., 1999; Johnson and Tyack, 2003; Sato et al., 2003; Wilson et al., 2008). Therefore, bio-logging methods should give researchers the means to assess the movement performance of the fast-start behaviours of fish in the wild. However, only a small number of studies have focused on assessing the movement performance of fast-start behaviour using data loggers (Bröell et al., 2013; Noda et al., 2013).

In laboratory-based studies, a number of variables, including maximum acceleration, angular velocity (e.g., turning rate), and movement direction (e.g., turning angle), have been found to be important for assessing the performance of fast-start movements (Harper and Blake, 1990; Domenici and Blake, 1991; Hale, 2002; Lefrançois and Domenici, 2006). Although many studies have used accelerometers to monitor the activities of fish in the wild (Kawabe et al., 2003; Tsuda et al., 2006; Wilson et al., 2008; Whitney et al., 2010; Bröell et al., 2013), an accelerometer alone may not be sufficient for obtaining accurate and detailed documentation of the 3D movements of the fast-start behaviour of animals because it is difficult to differentiate gravitybased acceleration (which can be converted to pitch and roll movements) 
from the dynamic acceleration that is included in accelerometer measurements (Fourati et al., 2010; Noda et al., 2012). Furthermore, rotational information, such as the angular velocity and direction of the movement, is lacking in these measurements.

Angular velocity can be directly measured with high temporal resolution (e.g. $100 \mathrm{~Hz}$ to $1 \mathrm{kHz}$ ) by a gyroscope. Using the gyroscope, if the initial attitude is known, any new attitude (hence, the gravity-based acceleration that would be measured by the accelerometer) can be estimated using initial attitude and the estimated attitude change calculated from the gyroscope measurements. An accelerometer and a magnetometer can be used in addition to a gyroscope to determine initial attitude and to correct the error when estimating attitude associated with the accumulation of noise from a gyroscope. In fact, a novel gyroscope data logger (hereafter, gyro logger), which incorporates a 3-axis gyroscope, a 3-axis accelerometer, and a 3-axis magnetometer (for a total of 9 axes), was developed. This device can reconstruct the fine-scale dynamic acceleration, gravity-based acceleration and attitude of animals (e.g. sea turtles), which have not been accurately measured in previous studies that only used an accelerometer (and occasionally a magnetometer) (Noda et al., 2012). Therefore, a gyro logger may be more suitable for monitoring the movement performance of fast-start behaviour in fish.

Given the above considerations, a novel gyro logger was developed and used in this study to investigate the possibility of using an animal-mounted data logger to monitor the movement performance of the fast-start behaviour of fish in the field. Specifically, the gyro logger was applied to measure the 
fast-start movements of a fish, the Japanese amberjack Seriola quinqueradiata, during escapes with a high sampling frequency $(500 \mathrm{~Hz})$. The link between escape movements and data logger measurements was thus explored. Although most previous studies have used a relatively low sampling frequency ( $\leq 32$ Hz) (Kawabe et al., 2003; Tsuda et al., 2006; Whitney et al., 2010; Føre et al., 2011), a higher sampling frequency was used in this study because faststart movements usually last only a fraction of a second. Our study focused on three questions: 1) Is it possible to accurately define locomotor variables from the gyro logger measurements? 2) Is it possible to define detailed variations in fast-start movements (e.g., single- vs. double-bend) from the gyro logger measurements? and 3) What are the advantages and disadvantages of using a gyro logger over a conventional accelerometer or high-speed imaging for measuring locomotor variables?

\section{Materials}

\section{Study animals}

The escape movements of five Japanese amberjacks [fork length (FL): 65.9 $\pm 0.45 \mathrm{~cm}$, body mass $(\mathrm{BM}): 4.08 \pm 0.78 \mathrm{~kg}$ ] (Table A1) were monitored in tank experiments at the Institute for East China Sea Research at Nagasaki University in Japan. The fish were obtained from a local fish hatchery (Nagasaki, Japan) and were maintained in a 300-cm-diameter outdoor tank with flow-through seawater at a temperature of $19.05 \pm 0.84{ }^{\circ} \mathrm{C}$, a depth of $1 \mathrm{~m}$, and a dissolved oxygen level of $84.89 \pm 3.88 \%$. The fish were acclimatised to the tank for at least one week prior to the initiation of experiments; after acclimatisation, the fish were tagged for the experiments. 


\section{Data logger}

A gyro logger (LP-BLKU01, Biologging Solutions Inc., Kyoto, Japan) was developed and used to record the 3-axial acceleration, 3-axial magnetism, and 3-axial angular velocity of the fish. This data logger was cylindrical in shape (diameter: $3 \mathrm{~cm}$, length: $17 \mathrm{~cm}$ ) with a mass of $108 \mathrm{~g}$ in air, which includes the attached CR123A battery. The measurement ranges were $\pm 16 \mathrm{~g}, \pm$ $100000 \mathrm{nT}$, and \pm 1500 degree second $^{-1}$ for the acceleration, magnetic field, and angular velocity, respectively. The resolution of the measurements was 16 bit $(-32768 \sim+32768): 4.88 \times 10^{-4} \mathrm{~g}, 3.05 \mathrm{nT}$, and $4.58 \times 10^{-2}$ degree second $^{-1}$ for the acceleration, magnetic field, and angular velocity, respectively. The data logger measured and stored all of the sensor outputs in an internal micro-SDHC memory $(\sim 32 \mathrm{~GB})$ at a sampling frequency of 500 $\mathrm{Hz}$ for a total sample time of 10 hours. Furthermore, this device allowed for multiple-scheduled recordings (e.g., 2 hours of recording each day). The data logger was covered with an alumite-treated case, which made it waterproof and pressure-proof up to a depth of $300 \mathrm{~m}$. The logger could also record temperature of range of $-45 \sim 80{ }^{\circ} \mathrm{C}$ and depth of up to 30 bar; however, only acceleration, magnetic data, and angular velocity were used for the analysis. A reflective marker was attached to the data logger for the video analysis (see below).

\section{Measurement of escape responses}

One week prior to the escape response measurements, the length and mass of the fish were measured under anaesthesia induced with phenoxyethanol $(<$ $0.05 \%)$. A plastic plate $\left(3 \times 18 \mathrm{~cm}^{2}\right)$ was sutured to the dorsal musculature just above the centre of mass (CM; $43 \%$ of the TL) using cable ties. 
The plate formed the base of the data logger. The position of the CM was determined by hanging a dead fish (different fish from those used for the activity measurements, $\mathrm{FL}=61.8 \mathrm{~cm}$ ) using a suture and needle (Lefrançois and Domenici, 2006). The temporary attachment of the gyro logger to the plastic plate base was accomplished using cable ties; the fish were sedated using anaesthesia during this procedure. The mass of the data logger was less than $3 \%$ of the body mass of the fish.

For the escape response measurements, gyro loggers were attached to five fish, which were then transferred from the holding tank to an identical and adjacent tank (300 $\mathrm{cm}$ in diameter). The water level in the experimental tank was maintained at $0.44 \mathrm{~m}$. The transfer and tagging time, which included the anesthetising time, was less than $5 \mathrm{~min}$. None of the animals exhibited any signs of stress, and they settled quickly into the experimental tank. The fish were allowed to acclimate to the experimental tank for at least 12 hours prior to the start of the escape measurements. The escape responses were triggered by randomly and manually thrusting a PVC pole with a length of $100 \mathrm{~cm}$ and diameter of $4.0 \mathrm{~cm}$ to the bottom of the tank [thrusting speed $=$ $0.80(0.34) \mathrm{m} \mathrm{s}^{-1}$ for the mean (s.d.), and $\mathrm{N}=24$ ] near the position of the fish when the fish were at least one body length from the tank wall. These responses were triggered at intervals of approximately $10 \mathrm{~min}$. Overall, 4 to 11 escape responses were recorded for each fish (Table A1).

The responses were also recorded using two video cameras located $2.85 \mathrm{~m}$ above the tank bottom: a 30-Hz standard USB webcam (HD C910, Logicool Co., Tokyo, Japan, with H264 Webcam 3.83 software, Timhillone software Co. Ltd., Nanshan, China) and a 200-Hz high-speed camera (HAS-L1, DI- 
TECT Co. Tokyo, Japan). The video cameras were controlled and manipulated using a connected PC. The high-speed camera was calibrated before the experiments by taking a picture of a checkerboard at the bottom of the tank. The relationship between the pixel size in the camera image and the actual distance was obtained by placing multiple markers at known interval distances along the bottom of the tank before the experiments. The clock times of the gyro loggers and the video recording were synchronised using the PC clock before the data loggers were attached to the fish. A reflective marker on the data loggers in the image sequences was digitised using Dipp-Motion PRO (DITECT Co. Tokyo, Japan). The acceleration and turning rate of the markers were derived using a five-point smoothing regression (Lanczos, 1956). The turning rate was obtained using two points: the snout of the fish and the marker on the data logger.

All experimental procedures were approved by the Animal Research Committee of Kyoto University (protocol number: Informatics 25-7).

\section{Methods}

The objective of this study was to reconstruct the locomotor variables of fast-start movements from the data logger measurements (Fig. 1). The estimation of the locomotor variables of the fast-start movements was divided into two parts:

- Reconstruction of the attitude and dynamic acceleration. Accelerometer measurements are usually modelled as a combination of linear, gravity-based, centripetal, and tangential accelerations. In this study, the acceleration components, including linear, centripetal and, tangen- 
tial accelerations, are referred to as dynamic acceleration (i.e., all of the components with the exception of gravity-based acceleration).

- Derivation of the locomotor variables (e.g., maximum acceleration, turning rate, and turning angle) using the reconstructed attitude (pitch, roll, and yaw), dynamic acceleration, and angular velocity. Dynamic acceleration was considered a time-distance variable. Angular velocity and attitude were considered angular variables.

\section{Reconstruction of attitude and dynamic acceleration}

The gyroscope measurements were used to determine the actual gravitybased acceleration from the accelerometer measurements. An accelerometer and a magnetometer were used to determine the initial attitude and to correct for any errors in the attitude estimation associated with the accumulation of gyroscope noise (e.g. Trawny and Roumeliotis, 2005; Sabatini, 2006; Fourati et al., 2010; Noda et al., 2012). The data logger was first calibrated according to previously described algorithms (Fong et al., 2008) for calibrating an accelerometer and a gyroscope and a two-step algorithm developed for calibrating a magnetometer (Gebre-Egziabher et al., 2001). To accurately estimate the attitude and dynamic acceleration by integrating the accelerometer, magnetometer, and gyroscope measurements, a previously described algorithm using an orientation filter (Madgwick et al., 2011) was adopted (hereafter, the gyro method).

\section{Reconstruction of locomotor variables}

Four coordinate frames were assumed: the earth frame, camera frame, fish frame and data logger frame (Fig. 2). The z-axis of the camera frame 
(vertical) was assumed to coincide with the z-axis of the earth frame (the $\mathrm{x}$ - and $\mathrm{y}$-axes do not necessarily coincide). A vector in one frame can be converted to a corresponding vector in another frame using a rotation matrix derived from the angular differences in pitch, roll, and yaw between the two frames (Titterton, 2005).

Ideally, the data logger frame should coincide with the fish frame; hence, the axes of the data logger measurements should coincide with the axes of the fish. However, in practice, it is sometimes difficult to attach a data logger such that its axes coincide with those of the fish. Therefore, after the data logger was attached, the fish was kept stationary and photographed on both its anterior and lateral sides. The angular differences in pitch and roll between the two frames were then calculated from these photos using a free image calculation software program (Image J 1.45, http://rsbweb.nih.gov/ij/). The yaw angle difference was assumed to be zero.

Because the fish frame and the earth frame change simultaneously as the fish moves, it was assumed that the movement in the earth frame would provide little insight into the forces acting on each dimension of the fish ( $\mathrm{x}-, \mathrm{y}-$, and z-axes). Therefore, the locomotor variables were represented in the fish frame after the appropriate coordinate conversions were made to more accurately describe the motions experienced by the fish. However, to compare the values of the locomotor variables obtained from the data logger measurements with those of the high-speed video camera images (see the Analysis), the locomotor variables obtained from the data logger measurements were converted to their corresponding values in the earth frame. 


\section{Time-distance variables}

Once attitude and dynamic acceleration were calculated, the dynamic acceleration could be processed to obtain linear acceleration, velocity, and displacement. Although dynamic acceleration usually includes tangential and centripetal acceleration as well as linear acceleration during the quick turning of escape movements, tangential and centripetal acceleration were not removed because the tuning radius, required for calculating the tangential and centripetal acceleration, is not measurable by the current gyro logger system alone. Note that turning rate and its derivative (angular acceleration) can be measured by a gyroscope. In addition, although the fish usually swim steadily before performing a fast-start movement (i.e., they do not stop before making rapid changes in motion; camera measurements indicated $0.33(0.04) \mathrm{m} \mathrm{s}^{-1}$ for the mean velocity (s.e.m.), and $\left.\mathrm{N}=24\right)$, the initial velocity was assumed to be zero because the current gyro logger cannot directly measure velocities. Thus, the dynamic acceleration (including the tangential and centripetal accelerations as well as the linear acceleration) was time-integrated to calculate velocity and displacement, which were termed relative velocity and relative displacement to distinguish these measurements from the true velocity and displacement (Fig. 1). Although the relative velocity and displacement are not the actual velocity and displacement of the fish in a physical sense, these values should represent relative values of the magnitude of the velocity and displacement as long as the onset of the time integration is determined using the same criteria and assuming that the fish swims at a similar speed before all fast-start movements. 
Angular variables

In the escape events, the turning rate, angles and duration of stage 1 and 2 [hereafter, S1 and S2, respectively; reviewed by (Domenici and Blake, 1997)] can be determined from the gyroscope measurements around the vertical axis (z-direction, as illustrated in Fig. 2) and the yaw angles (Fig. 3). Similar to Domenici and Blake (1997), it was defined that S1 begins at the first detectable movement of the fish and is completed when the turning ratetime curve crosses the (turning rate $=0$ ) axis. The onset of $\mathrm{S} 2$ coincides with the end of S1, and S2 ends when the turning rate-time curve crosses the (turning rate $=0$ ) axis again.

\section{Analysis}

The programs used for calibrating the data logger measurements, extracting data for the fast-start events, and reconstructing locomotor variables from the data logger measurements were all created in Igor Pro 6.3 (WaveMetrics, Inc. Tigard, OR, USA). Statistical analyses were performed using R 2.15 (the R Foundation for Statistical Computing).

Comparison of the locomotor variables of the data logger measurements and high-speed video camera recordings

In this analysis, the accuracy of the reconstructed locomotor variables from the gyro logger measurements was examined. Assuming that the z-axis of the earth frame coincides with the z-axis of the camera frame, the dynamic acceleration of the combined $\mathrm{x}$ - and $\mathrm{y}$-directions in the earth frame obtained from the data logger measurements (see the Appendix for the calculation) was compared with the acceleration measured by the video camera. The rel- 
ative velocity and cumulative distance of the combined $\mathrm{x}$ - and $\mathrm{y}$-directions in the earth frame obtained from the data logger measurements were also compared with the velocity and cumulative distance obtained from the camera measurements. Two dimensional trajectory ( $\mathrm{x}-\mathrm{y}$ surface) measured by the data logger was compared with the trajectory measured by the camera. The angular velocity and angle of the yaw direction in the earth frame obtained from the data logger measurements were compared with the turning rate and angle measured by the video camera. Specifically, a regression analysis of the following variables between the two measurements was conducted for the comparisons: maximum acceleration, maximum velocity, cumulative distance, turning rate, S1 and S2 angles, and S1 and S2 durations. Maximum acceleration, maximum velocity, cumulative distance, and 2D trajectory were measured for a fixed duration of $0.18 \mathrm{~s}$ from the onset of the escape movements, which was chosen by calculating the mean of the $(\mathrm{S} 1+\mathrm{S} 2)$ durations of events that clearly showed the end of stage 2 [this occurred in 9 out of 24 events that were simultaneously recorded with the high-speed camera]. The turning rate was calculated as S1 angle / S1 duration (Domenici and Blake, 1991). Mean Euclidean distance was calculated from the 2D trajectory between the data logger and camera measurements.

\section{Variations in escape movements}

The escape movements were divided into different mechanical types (singleand double-bend) using the film images following Domenici and Blake (1991). Then, to investigate whether the gyro logger measurements can be used to identify the variations in escape movements, the locomotor variables obtained from the gyro logger measurements of escape events were compared between 
the two types of escape movements. The following locomotor variables were then examined in detail: time-distance variables [maximum acceleration and relative velocity in the $\mathrm{x}-, \mathrm{y}-$, and $\mathrm{z}$-directions; maximum of the MA and the magnitude of the relative velocity (MV, vector summation of the relative velocity along the $\mathrm{x}-, \mathrm{y}$ - and, $\mathrm{z}$-axes); relative cumulative distance], angular variables (maximum angular velocity in the $\mathrm{x}-, \mathrm{y}-$, and $\mathrm{z}$ - directions; S1 angle; range of pitch and roll), and time variables [S1 duration; difference in the time required to reach the maximum acceleration between the $\mathrm{x}$ - and y-positions $\left(T_{x}-T_{y}\right)$ and between the $\mathrm{x}$ - and z-positions $\left(T_{x}-T_{z}\right)$; time required to reach the maximum MA and MV]. All of the variables except for the $\mathrm{S} 1$ angle were measured for a fixed duration of $0.18 \mathrm{~s}$ from the onset of the escape movements. The maximum acceleration was obtained from the absolute value of the acceleration in each direction because the sign of the accelerometer measurements is not important when considering the maximum force acting on the fish. A repeated measure ANOVA (RM-ANOVA) was performed on each locomotor variable using the mechanical movement types as fixed factors and the individual fish as random factors.

Comparison of the gyro and smoothing methods for deriving acceleration variables

The advantages of using the gyro logger to derive locomotor variables were examined by comparing the locomotor variables obtained using a conventional accelerometer with those obtained using a gyro logger. If a gyroscope is not available, it may be impossible to accurately derive acceleration variables such as the maximum dynamic acceleration because the value of the true gravity-based acceleration, which is included in the accelerometer 
measurements, is not known. In previous works, the gravity-based acceleration has been determined by smoothing (Wilson et al., 2006; Shepard et al., 2008) or low-pass filtering (Sato et al., 2003; Tanaka et al., 2001) methods. It is therefore useful to investigate whether smoothing the measurements obtained from an accelerometer is sufficient to assess the performance of faststart movements. Because the smoothing and low-pass filtering methods are both based on the same principle, only the smoothing technique was examined in this study. The effect of the extent of smoothing on the accuracy of the derived acceleration variables was determined through a comparison to the values derived from the gyro logger measurements. The investigated acceleration variables were the maximum, mean, standard deviation (s.d.), and root mean square (RMS) of the acceleration in the $\mathrm{x}-, \mathrm{y}-$, and z-directions, the overall dynamic body acceleration [ODBA, which combines the absolute dynamic acceleration values in the 3 axial directions (Wilson et al., 2006; Shepard et al., 2008)], and the time to maximum acceleration in the $\mathrm{x}-$, $\mathrm{y}-$, and z-directions. All of the variables were measured using data that were extracted such that the maximum peak of the MA was mapped to the centre of the duration (1 s).

\section{Results}

All of the escape movements ( $\mathrm{N}=11,8,11,4$, and 7 from 5 different fish, for a total of 41 events) were simultaneously recorded by a data logger and a normal $30-\mathrm{Hz}$ video camera (Table A1). In addition, 24 of the escape events $(4,5,8,3$, and 4 events for 5 different fish) were also simultaneously recorded with a $200-\mathrm{Hz}$ high-speed video camera (Table A1). 
Comparison of the locomotor variables obtained from the data logger measurements and from the high-speed video camera recording

The cumulative distance, velocity, acceleration, turning rate, and turning angle obtained from the gyro logger measurements typically exhibited similar profiles to those from the video recordings (Fig. 4a). In the two escape events of the camera recordings, the angular variables were not obtained because the snout of the fish was not clearly visible in the film images due to low contrast with the background. Because there were two types of movement in the escape response (single- and double-bend; for the detail, see the next section), S2 angle and duration were obtained only for the double-bend events. A regression analysis of all of the variables except for the maximum acceleration between the camera and data logger measurements indicated a statistically linear relationship [(a) cumulative distance: Video $=1.08 \times$ Logger +0.02 ; $R^{2}=0.85 ; \mathrm{F}$ value $=128.60(1$ and 22 Degree of Freedom (D.F.) $) ; \mathrm{p}<0.0001 ;$ $\mathrm{N}=24$, (b) maximum velocity: Video $=0.85 \times$ Logger $+0.21 ; R^{2}=0.56 ; \mathrm{F}$ value $=28.47$ ( 1 and 22 D.F.); $\mathrm{p}<0.0001 ; \mathrm{N}=24$, (c) maximum acceleration: $R^{2}=0.01 ; \mathrm{F}$ value $=0.13(1$ and 22 D.F. $) ; \mathrm{p}=0.73 ; \mathrm{N}=24,(\mathrm{~d})$ turning rate: Video $=0.78 \times$ Logger $+102.98 ; R^{2}=0.53 ; \mathrm{F}$ value $=22.36(1$ and 20 D.F. $)$ $\mathrm{p}<0.001 ; \mathrm{N}=22$, (e) S1 angle: Video $=0.95 \times$ Logger $+6.86 ; R^{2}=0.41 ; \mathrm{F}$ value $=13.95(1$ and 20 D.F. $) ; \mathrm{p}<0.01 ; \mathrm{N}=22$, (f) S2 angle: Video $=0.97$ $\times$ Logger $-2.20 ; R^{2}=0.93 ; \mathrm{F}$ value $=108.6(1$ and 8 D.F. $) ; \mathrm{p}<0.0001 ; \mathrm{N}=$ 10, (g) S1 duration: Video $=1.02 \times$ Logger $-0.00 ; R^{2}=0.99 ; \mathrm{F}$ value $=2785$ (1 and 20 D.F.); $\mathrm{p}<0.0001 ; \mathrm{N}=24$, (h) S2 duration: Video $=0.98 \times$ Logger $+0.00 ; R^{2}=0.97 ; \mathrm{F}$ value $=263.2(1$ and 8 D.F. $) ; \mathrm{p}<0.0001 ; \mathrm{N}=10$ ] (Fig. 5). There were larger variations in the maximum acceleration between the 
camera and data logger measurements (Fig. 5). Compared to the S2 angle and S1 and S2 durations, the S1 angle and turning rate exhibited greater variability between the camera and data logger measurements (Fig. 5). The 2D trajectory obtained from the data logger also exhibited similar profiles to the trajectory from the video recordings (Fig. 4b); the mean Euclidean distance was $0.032(0.017) \mathrm{m}$ for the mean (s.e.m.).

Variations in escaping movements

Image sequences of the escape events captured by the high-speed camera were used to categorise the fast-start movements into two types of escape movements based on the bending (Domenici and Blake, 1997): single-bend ( $\mathrm{N}=3,2,4,3$, and 1 for the 5 fish, for a total of 13 events) and double-bend ( $\mathrm{N}=1,3,4,0$, and 3 for the 5 fish, for a total of 11 events). In the single-bend escape movement, the fish bends into a $\mathrm{C}$ shape and subsequently straightens without bending in the opposite direction (Fig. A1a). In the double-bend escape movement, the fish performs a full return flip of the tail after the initial contraction (Fig. A1b). The differences in these movements were clear in the sensor-derived locomotor variables. The fish bent at significantly larger angles and exhibited larger S1 angles in the single-bend response than in the double-bend response (Fig. 6, Table 1). The maximum acceleration and angular velocity were significantly lower in the single-bend response movements than in double-bend responses (Fig. 6, Table 1). In addition, the fish moved a significantly shorter cumulative distance in the single-bend response (Fig. 6, Table 1). In the single-bend response, the maximum acceleration in the lateral direction was reached before the maximum acceleration in the forward direction was achieved, whereas in the double-bend movements, the 
maximum acceleration in the lateral direction was reached after the maximum acceleration in the forward direction was obtained; these results were found to be significantly different (Fig. 6, 7, Table 1).

Comparison of the gyro and smoothing methods for deriving acceleration variables

The effect of the extent of smoothing employed to determine the gravitybased acceleration on the accuracy of the derived acceleration variables was assessed. The percent changes in the maximum, s.d., and RMS of the dynamic acceleration and the ODBA decreased and appeared to stabilise when the running-mean duration increased; in fact, this change was small and nearly stable (less than $10 \%$; the ODBA obtained from the gyro method was $1.23 \mathrm{~g}$ ) when the running-mean duration was more than approximately $0.3 \mathrm{~s}$ (Fig.8, Table 2). However, the percent change of the mean dynamic acceleration was more than $95 \%$ regardless of the running-mean duration (Table 2). Note that the smoothing technique was not capable of estimating the true values of the acceleration variables, the gravity-based acceleration or the dynamic acceleration (Fig. 9, Table 2). For example, the RMS values of the difference in the gravity-based accelerations determined using the gyro and smoothing methods with a running-mean duration of $0.3 \mathrm{~s}$ for $1 \mathrm{~s}$ of measurement data were 0.211 (0.019), 0.274 (0.021) and $0.151(0.008) g$ for the mean (s.e.m.), respectively for the $\mathrm{x}-, \mathrm{y}-$, and z-directions in the escape events, which are significantly larger than the values of 0.021 (0.004), 0.013 (0.002) and $0.017(0.002) g$ measured in routine movements [paired t-test $(\mathrm{N}$ $=41) ; \mathrm{p}<0.001, \mathrm{p}<0.001$, and $\mathrm{p}<0.001$ for the $\mathrm{x}-, \mathrm{y}_{-}^{-}$, and $\mathrm{z}$-directions, respectively]. The percent change in the time required to reach the maximum 
dynamic acceleration was small (less than $2 \%$ ) and stable regardless of the running-mean duration (Table 2).

\section{Discussion}

Accuracy of the gyro logger for monitoring the locomotor variables of faststart movements

Cumulative distance, velocity, acceleration, turning rate and turning angle have been important variables with which to assess the movement performance of fast-start fish (Harper and Blake, 1990; Domenici and Blake, 1991; Hale, 2002; Lefrançois and Domenici, 2006). In addition to the similar profiles of the graphed variables between the camera and data logger measurements, the statistically significant linear relationships between most of the locomotor variables (cumulative distance, maximum velocity, turning rate, S1 and S2 angles, and S1 and S2 durations) obtained from the gyro logger measurements and the camera recordings indicate that the gyro logger measurements can be used to assess movement performance. The statistically significant linear relationships even from the relative values of the cumulative distance and velocity obtained by the gyro logger may indicate that those values can also be used as a performance measure. This may be also supported by the similar profiles of the 2D trajectory and small mean Euclidean distance between the data logger and camera measurements. Although there was large variability and no significant relationship was found between the data logger and camera measurements for maximum acceleration, considering that the accelerometer itself produces a high accuracy for measuring acceleration, the variability may mostly result from the digitisation error of the camera record- 
ings: the acceleration in the camera recordings is derived from the second differential of the digitised points, whereas the acceleration in the accelerometer is directly measured. This may be supported by the fact that velocity and cumulative distance, which are the first and second integrals of acceleration and can thus accumulate a large error from any misdetermination of the dynamic acceleration, exhibited more similar values to those obtained by the camera recordings than the accelerations. Although a common method was utilised for smoothing the digitised points [a five-point smoothing regression (Domenici and Blake, 1991; Domenici et al., 2004; Lefrançois et al., 2005)], it is possible that the image magnification and the film rate were not high enough to obtain accurate estimates of maximum acceleration from the digitised points (Harper and Blake, 1989). Not removing tangential and centripetal acceleration from the accelerometer measurements may also result in the error between the data logger and camera measurements, although maximum acceleration would be much less influenced by tangential acceleration (Harper and Blake, 1990).

The error in the angular variables between the two measurements, especially in the turning rate and S1 angle, may result from the difference in the places where the turning rate and angles were measured. In the camera recordings, the turning rate and angle were obtained using two points: the snout of the fish and the marker on the data logger attached to the dorsal musculature approximately above the fishs $\mathrm{CM}$, following previous research (Domenici and Blake, 1991; Domenici et al., 2004; Hale, 2002). On the other hand, the turning rate and angle measured by the gyro logger should correspond with those obtained from the camera recordings using two points on 
the data logger along the longitudinal direction (e.g., tip and centre). Therefore, when the fish bends deeply, typically during a single-bend response, the line between the snout and the marker on the data logger would produce a larger angle than that between the two points on the data logger along the longitudinal direction. During a double-bend response, the error would be smaller because the bending of the fish is shallower. However, the difference between the camera and the gyro logger in the place where the turning rate was measured produced little effect on the S1 and S2 durations, possibly because the timing of the movement change is almost the same between the two lines.

Overall, these results suggest that it is possible to use the data logger measurements for assessing movement performance, although care must be taken when interpreting and comparing the locomotor variables obtained by the data logger measurements with those obtained from camera recordings in previous research. The error of the $2 \mathrm{D}$ trajecotry, cumulative distance and velocity between the data logger and camera measurements will be mitigated using a speed sensor (such as a propella) additionally.

\section{Variation in escape movements}

It was possible to identify the variation in escape movements using the data logger measurements. In this study, escape movements were classified into two distinct mechanical types (single- and double-bend), consistent with previous results for other fish (Domenici and Blake, 1991; Kasapi et al., 1993; Jing et al., 2004; Lefrançois et al., 2005; Jing et al., 2005). The different mechanical types of escape movements were clearly reflected in the timing of maximum acceleration in the lateral and forward directions as well as other 
locomotor variables: the timing difference has not reported in the previous research. In the single-bend movements, maximum acceleration in the lateral direction occurs before maximum acceleration in the forward direction. This result is reasonable considering that, in the single-bend movements, the fish turns away from an offending stimulus by bending into a C-shape in stage 1, which results in the occurrence of a lateral movement prior to forward propulsion (forward direction). In the double-bend movements, maximum acceleration in the lateral direction occurs after maximum acceleration in the forward direction. This result is also reasonable because, although strong forward acceleration occurs after an initial bend with a small turning angle, the second bend that occurs later in the double-bend movement may exhibit a stronger lateral acceleration than the initial bend to maintain or increase the forward velocity and the distance covered. Therefore, the difference in the timing of maximum acceleration along these two axes may be a simple yet powerful parameter for distinguishing between these two types of movement.

Advantages and disadvantages of using a gyro logger over conventional methods

Comparison with an accelerometer

Although smoothing (Wilson et al., 2006; Shepard et al., 2008) is commonly used to determine gravity-based acceleration from accelerometer measurements, the acceleration variables can be affected by the extent of smoothing used. This study indicated that the percent change of the measured variables (the ODBA, maximum, s.d., and RMS of acceleration, and the time required to reach maximum acceleration) obtained from the smoothing method decreased (less than $10 \%$ using a duration of $0.3 \mathrm{~s}$ ) compared to 
that obtained using the gyro method and became nearly stable when the running-mean duration increased. This result indicates that if the appropriate running-mean duration is set, the acceleration variables determined through the smoothing method may become stable and thus less prone to error (in this case, a duration of more than $0.3 \mathrm{~s}$ to decrease the error rate less than 10 \%). Although previous studies (Shepard et al., 2008; Halsey et al., 2009) have used steady swimming and walking behaviour to examine the variability of the ODBA as a function of the extent of smoothing, the variability of the ODBA in fast-start movements has not yet been assessed. This study showed that the ODBA was stable with a smaller running-mean duration $(0.3 \mathrm{~s})$ for the fast-start movements of this fish species in comparison to the duration obtained for the steady swimming of other animals [3 s (Shepard et al., 2008)]. This difference may arise because fast-start movements occur within a fraction of a second, a duration that is generally shorter than the duration of 1 cycle of propulsion during steady swimming. In addition, because the scale of the ODBA is much larger in fast-start movements (more than $1.2 \mathrm{~g}$ ), the small error caused by the extent of smoothing may be negligible.

The percent change in the time required to reach maximum acceleration was less than $1 \%$, which indicates that this parameter may be stable regardless of the extent of smoothing used. Because the timing of maximum acceleration in the $\mathrm{x}$ - and $\mathrm{y}$-directions was found to be a powerful parameter (as described above) for distinguishing between the different mechanical types of movements, this variable may also be used to categorise movement types regardless of the extent of smoothing. However, the mean acceleration 
changed significantly (more than $90 \%$ ) regardless of the extent of smoothing, which indicates that mean acceleration cannot be assessed from the values obtained through the smoothing method. It is possible that the smoothing method is not capable of accurately reconstructing dynamic acceleration; in addition, mean acceleration is significantly affected by the accuracy of the dynamic acceleration estimate compared to other acceleration metrics (i.e., the ODBA, maximum, s.d., and RMS of acceleration and the time required to reach maximum acceleration).

The extent to which the misdetermination of gravity-based acceleration based on the smoothing method affects the accuracy of estimated acceleration variables may depend on the intensity and range of the acceleration. In the fast-start movements of the fish studied herein, the mean maximum acceleration was approximately $5 \sim 10 \mathrm{~g}$. Because the range of gravity-based acceleration was -1 1 $g$, the error of the gravity-based acceleration determined by the smoothing method is at most $2 g$. Therefore, if the intensity and range of the acceleration are small, the error in the gravity-based acceleration due to the smoothing process may result in a significant under- or over-estimation of the acceleration variables, whereas the error may be negligible if the intensity and range of the acceleration are large. The intensity and range of the acceleration will vary depending on the species, context (temperature, motivation, etc.) (Lefrançois and Domenici, 2006; Marras et al., 2011), and even the position at which the data logger is attached to the fish. However, because the error rate becomes stable after a sufficient running-mean duration in the fast-start context, it might be possible to obtain reasonably accurate acceleration variables by smoothing the measurements obtained from an ac- 
celerometer (without a gyroscope) once the error rate is estimated; this is only possible if the accelerometer is applied to the same species at a similar attachment location and if acceleration variables similar to those examined in this study are obtained (except for the mean acceleration).

The advantage of using measurements from a gyro logger over those obtained from an accelerometer is that gravity-based acceleration can be easily and clearly removed from the measurements, which means that the acceleration variables can be accurately derived. In addition, gyro logger measurements can be used to calculate additional data, such as attitude, angular velocity, relative velocity, and relative cumulative distance (displacement), which cannot be obtained from an accelerometer alone. Although most of the acceleration variables calculated in this study became stable once an appropriate running-mean duration had been set, the smoothing procedure could not be used to accurately estimate gravity-based acceleration in fast-start movements in which dynamic acceleration and attitude (hence, gravity-based acceleration) change rapidly and exhibit a stronger intensity in comparison to steady swimming movements. A previous study (Noda et al., 2012) found that the error of the gravity-based acceleration RMS produced by smoothing data obtained for the steady swimming of green sea turtles was less than $0.1 \mathrm{~g}$. However, the error in the RMS was much larger (greater than $0.15 \mathrm{~g}$ ) in the fast-start movements examined in this study. Thus, the gyro logger can be used to accurately gain information on distance-related performance and manoeuvrability parameters, which will prove effective in the analysis of fast-start movements involving a rapid change in motion. 
Comparison with high-speed imaging

The most important advantage of a data logger is that it can measure the locomotion of animals in the field. High-speed imaging with a camera has an advantage over data logger methods because it does not require attachment to an animal. Furthermore, high-speed imaging can be used to simultaneously track multiple individuals (Kane et al., 2004; Lochmatter et al., 2008). Kinematics and mechanics information can be obtained from the images to interpret fast-start movements and to assess the performance of the movements. The latency and prey reaction distance, as defined in the predator-prey relationship, can also be measured. Although many previous studies have studied the 2D locomotion of fast-start movements, high-speed imaging-based methods have recently been developed for monitoring the 3D locomotion of fast-start movements (Butail and Paley, 2011). However, highspeed imaging is very difficult to implement in the field, especially for monitoring highly migratory or elusive animals. As described in this study, a gyro logger can be used to directly monitor all of the 3D forces acting on the body of an animal. Although the data logger must be attached to the body of the animal and recovered at the end of the measurement period to obtain the data stored in the internal memory of the device, this instrument can be used to measure the movement of animals in the wild. Although data logger measurements can only partially capture the movement of the body and although some of the movements, such as the movement of an appendage, are not measurable, once links between data logger measurements and the mechanical types of movements are established, we may be able to obtain a clearer picture of the movements of animals, as shown in this study. 
Application of the developed method

The method developed in this study can be used for assessing the movement performance of the fast-start behaviour of fish in the field. Although laboratory settings enable controlled experiments, measuring locomotion in natural settings is also important. For example, to understand animals energetic strategies, it is important to know when and under what type of environmental conditions they conduct escape behaviours and how much power they use for their escape, as it is not always necessary for animals to use maximum performance (Irschick, 2003), and fast-start behaviour typically involves a high energy requirement (Domenici and Blake, 1997).

The limitations of this method include the data logging duration. Although most studies have used a relatively low sampling frequency $(\leq 32$ Hz) (Kawabe et al., 2003; Tsuda et al., 2006; Whitney et al., 2010; Føre et al., 2011), this study used a high frequency $(500 \mathrm{~Hz})$ because fast-start movements usually last only a fraction of a second (reviewed by Domenici and Blake, 1997). Consequently, a sufficiently high sampling frequency is required to monitor these behaviours. However, high-frequency sampling requires more battery power and thus the total recording duration is limited. If the battery size, and thus the total recording duration, increases, the size of the data logger also has to be increased, which limits the size range of the animals for which the data logger is applicable. The addition of a gyroscope to the conventional sensors such as an accelerometer and a magnetometer also requires more battery power. Although this study cannot solve the technological issues around the batteries, sampling frequencies, and sensor types, it does address the possibility of using animal-mounted data loggers for mea- 


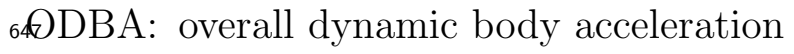

${ }_{648}$ RMS: root mean square

649 S1: stage 1

${ }_{650} \quad$ S2: stage 2

${ }_{651} T_{x}$ : the time required to reach the maximum acceleration in the $\mathrm{x}$ axis

${ }_{652} T_{y}$ : the time required to reach the maximum acceleration in the $\mathrm{x}$ axis

${ }_{653} T_{z}$ : the time required to reach the maximum acceleration in the $\mathrm{x}$ axis 


\section{Appendix}

Calculation of the dynamic acceleration of the combined $x$ - and $y$-directions

The acceleration obtained by video tracking is defined in the coordinate fixed to the tank (camera frame), whereas the acceleration obtained by the accelerometer is defined in the coordinate fixed to the data logger (logger frame) (Fig. 1). Because, from the view of the camera frame, the logger frame always changes when the data logger moves with the body of the fish, it is necessary to transform the acceleration obtained by the accelerometer to the acceleration that would be sensed in the camera frame to compare the two accelerations. To achieve that transformation, the following calculation was performed:

It was assumed that the logger frame coordinate is defined as a coordinate composed of two vectors, one of which is the vector ( $Y_{A}$ axis) connecting the two markers on the accelerometer in the longitudinal direction and the other is the vector $\left(X_{A}\right.$ axis) perpendicular to the $Y_{A}$ axis going through the centre of the two markers. Assume $M_{t}, M_{t+1}$, and $M_{t+2}$ to be the 2D points of the centre of the two markers obtained by the video tracking at time $t, t+1$, and $t+2$, respectively, in the camera frame coordinates. The acceleration obtained by video tracking at time $t$ should be defined as the acceleration measured in terms of the change in the points $M_{t}, M_{t+1}$, and $M_{t+2}$ with the direction $\vec{\mu}$ from $M_{t}$ to $M_{t+2}$. On the other hand, the acceleration obtained by the accelerometer at time $t$ is defined as the acceleration in the two directions $\overrightarrow{\mu_{x}}$ and $\overrightarrow{\mu_{y}}$, respectively, in the $X_{A}$ axis and the $Y_{A}$ axis direction in the logger frame coordinate. Therefore, two accelerations, $A x_{t}$ and $A y_{t}$, measured by the accelerometer can be transformed to the combined acceleration $A v_{t}$ in 
the $\vec{\mu}$ direction that would be measured in the camera frame by the vector summation of $\overrightarrow{\mu_{x}}$ and $\overrightarrow{\mu_{y}}$ with the scalar of $\sqrt{A x_{t}^{2}+A y_{t}^{2}}$.

\section{Table A1}

Summary of the total (TL) and fork (FL) lengths, body mass (BM), and number of observed escape $\left(\mathrm{N}_{e}\right)$ activities identified using the video images for 5 (A-E) different Japanese amberjacks. The $\mathrm{N}_{e}$ number in parentheses indicates the number of escape responses that were simultaneously recorded with a high-speed camera.

\section{Figure A1}

Image sequences of a) single- and b) double-bend escape movements.

\section{Acknowledgements}

The authors would like to thank Nishihara G.N. for lending us a PC and the digitisation software used in this study. We also appreciate Kawabe R., Furukawa S., Nakatsuka N., and all of the staff at the Institute for East China Sea Research at Nagasaki University for their help with the experiments.

\section{Author Contributions}

T.N., N.A. and H.M. designed and developed a gyro logger. T.N., Y.K., N.A., and H.M. contributed to the design of the experimental study. T.N., Y.K. and S.W. contributed to the execution of the experiments. T.N. analyzed the data and wrote the manuscript. All authors provided critiques on the research and the manuscript. 


\section{Funding}

This research was partly supported by a Research Fellowship from the Japan Society for the Promotion of Science (No. 10J06259 to T.N.), a grant from the Special Coordination Funds for Promoting Science and Technology, funded by The Japan Science and Technology Agency, to Y.K., a Grant-inAid for Research Activity start-up (No. 23880023 to Y.K.), a Grant-in-Aid for Young Scientists (No. 21688015 to H.M.), a fellowship from the Nakajima Foundation to H.M., and the GCOE program Informatics Education and Research Centre for Knowledge-Circulating Society.

\section{References}

Bröell F., Noda T., Wright S., Domenici P, Steffensen J.F., Auclair J.P., Taggart C.T., 2013. Accelerometer tags: detecting and identifying activities in fish and the effect of sampling frequency. J. Exp. Biol. 216, 1255-1264.

Butail S., Paley D.A., 2011. Three-dimensional reconstruction of the faststart swimming kinematics of densely schooling fish. J. R. Soc. Interface. $9,77-88$.

Cooke S.J., Hinch S.G., Wikelski M., Andrews R.D., Kuchel L.J., Wolcott T.G., Butler P.J., 2004. Biotelemetry: a mechanistic approach to ecology. Trends Ecol. Evol. 19, 334-343.

Davis R.W., Fuiman L.A., Williams T.M., Collier S.O., Hagey W.P., Kanatous S.B., Kohin S., Horning M., 1999. Hunting behavior of a marine mammal beneath the antarctic fast Ice. Science 283, 993-996. 
Domenici P., Batty R.S., Simila T., Ogam R., 2000. Killer whales (Orcinus orca) feeding on schooling herring (Clupea harengus) using underwater tailslaps: kinematic analyses of field observations. J. Exp. Biol. 203, 283-294.

Domenici P., Blake R.W., 1991. The kinematics and performance of the escape response in the angelfish (Pterophyllum eimekei). J. Exp. Biol. $156,187-205$.

Domenici P., Blake R.W., 1997. The kinematics and performance of fish fast-start swimming. J. Exp. Biol. 200, 1165-1178.

Domenici P, Standen E.M., Levine R.P., 2004. Escape manoeuvres in the spiny dogfish (Squalus acanthias). J. Exp. Biol. 207, 2339-2349.

Elkaim G.H., Decker E.B., Oliver G., Wright B., 2006. Development of a marine mammal marker (mammark) for in-situ environmental monitoring. Proc. ION-NTM 2006.

Fong W.T., Ong S.K., Nee A.Y.C., 2008. Methods for in-field user calibration of an inertial measurement unit without external equipment. Meas. Sci. Technol. 19, 085202

Føre M., Alfredsen J.A., Gronningsater A., 2011. Development of two telemetry-based systems for monitoring the feeding behaviour of Atlantic salmon (Salmo salar L.) in aquaculture sea-cages. Comput. Electron. Agr. $76,240-251$.

Fourati H., Manamanni N., Afilal L., Handrich Y., 2010. Posture and body acceleration tracking by inertial and magnetic sensing: Application in be- 
havioral analysis of free-ranging animals. Biomed. Signal. Proces. 6, 94104.

Gebre-Egziabher D., Elkaim G.H., Powell J.D., Parkinson B.W., 2001. A non-linear, two-step estimation algorithm for calibrating solid-state strapdown magnetometers. Proc. Int. Conf. Integ. Navigation Systems. 28-30.

Hale M.E., 2002. S- and C-start escape responses of the muskellunge (Esox masquinongy) require alternative neuromotor mechanisms. J. Exp. Biol. 205, 2005-2016.

Halsey L.G., Green J.A., Wilson R.P., Frappell P.B., 2009. Accelerometry to estimate energy expenditure during activity: best practice with data loggers. Physiol. Biochem. Zool. 82, 396-404.

Harper D.G., Blake R.W., 1990. Fast-Start Performance of Rainbow-Trout Salmo-Gairdneri and Northern Pike Esox-Lucius. J. Exp. Biol. 150, 321342.

Harper D.G., Blake R.W., 1989. Short communication: A critical analysis of the use of high-speed film to determine maximum accelerations of fish. J. Exp. Biol. 142, 465-471.

Higham T.E., 2007. The integration of locomotion and prey capture in vertebrates: Morphology, behavior, and performance. Integr. Comp. Biol. 47, 82-95.

Irschick D.J., 2003. Measuring Performance in Nature: Implications for Studies of Fitness Within Populations. Integr. Comp. Biol. 43, 396-407. 
Jing J, Li S., Lu X., Yin X., 2004. The Kinematic Analysis of C-start in Crucian Carp (Carassius Auratus). Exp. Mech..

Jing J., Yin X., Lu X., 2005. Observation and hydrodynamic analysis of fast-start of yellow catfish (Pelteobagrus fulvidraco). Prog. Natural Sci. 15, 34-40.

Johnson M.P., Tyack P.L., 2003. A digital acoustic recording tag for measuring the response of wild marine mammals to sound. IEEE J. of Oceanic Eng. 28, 3-12.

Kane A.S., Salierno J.D., Gipson G.T., Molteno T.C.A., Hunter C., 2004. A video-based movement analysis system to quantify behavioral stress responses of fish. Water Res. 38, 3993-4001.

Kasapi M.A., Domenici P., Blake R.W., Harper D., 1993. The kinematics and performance of escape responses of the knifefish Xenomystus nigri. Can. J. Zool. 71, 189-195.

Kawabe R., Nashimoto K., Hiraishi T., Naito Y., Sato K., 2003. A new device for monitoring the activity of freely swimming flatfish, Japanese flounder Paralichthys olivaceus. Fisheries Sci. 69, 3-10.

Lanczos C, 1956. Applied Analysis. Prentice Hall. Eaglewood Cliffs, New Jersey.

Lefrançois C., Domenici P., 2006. Locomotor kinematics and behaviour in the escape response of European sea bass, Dicentrarchus labrax L., exposed to hypoxia. Mar. Biol. 149, 969-977. 
Lefranc cois C., Shingles A., Domenici P., 2005. The effect of hypoxia on locomotor performance and behaviour during escape in Liza aurata. J. Fish Biol. 67, 1711-1729.

Lochmatter T., Roduit P., Cianci C., Correll N., Jacot J., Martinoli A., 2008. SwisTrack - a flexible open source tracking software for multi-agent systems. IRE Prof. Group Audio. 4004-4010.

Madgwick S.O.H, Harrison A.J.L., Vaidyanathan R., 2011. Estimation of IMU and MARG orientation using a gradient descent algorithm. IEEE Int. Conf. on Rehabilitation Robotics. 1-7.

Marras S., Killen S.S., Claireaux G., Domenici P., McKenzie D.J., 2011. Behavioural and kinematic components of the fast-start escape response in fish: individual variation and temporal repeatability. J. Exp. Biol. 214, 3102-3110.

Mitani Y., Sato K., Ito S., Cameron M.F., Siniff D.B., Naito Y., 2003. A method for reconstructing three-dimensional dive profiles of marine mammals using geomagnetic intensity data: results from two lactating Weddell seals. Polar Biol. 26, 311-317.

Murchie K.J., Cooke S.J., Danylchuk A.J., Suski C.D., 2011. Estimates of field activity and metabolic rates of bonefish (Albula vulpes) in coastal marine habitats using acoustic tri-axial accelerometer transmitters and intermittent-flow respirometry. J. Exp. Mar. Biol. Ecol., 396, 147-155.

Noda T., Okuyama J., Koizumi T., Arai N., Kobayashi M., 2012. Monitoring 
attitude and dynamic acceleration of free-moving aquatic animals using a gyroscope. Aquat. Biol. 16, 265-276.

Noda T., Kawabata Y., Arai N., Mitamura H., Watanabe S., 2013. Monitoring escape and feeding behaviours of cruiser fish by inertial and magnetic sensors. PLOS ONE. journal.pone.0079392.

Rutz C., Hays G.C., 2009. New frontiers in biologging science. Biology lett. 289-292.

Sabatini A.M., 2006. Quaternion-based extended Kalman filter for determining orientation by inertial and magnetic sensing. IEEE Trans. Biomed. Eng. 53, 1346-1356.

Sato K., Mitani Y., Cameron M.F., Siniff D.B., Naito Y., 2003. Factors affecting stroking patterns and body angle in diving Weddell seals under natural conditions. J. Exp. Biol. 206, 1461-1470.

Schriefer J.E., Hale M.E., 2008. Strikes and startles of northern pike (emphEsox lucius): a comparison of muscle activity and kinematics between S-start behaviors. J. Exp. Biol. 207, 535-544.

Shepard E.L.C., Wilson R.P., Halsey L.G., Quintana F., Gómez-Laich A., Gleiss A.C., Liebsch N., Myers A.E., Norman B., 2008. Derivation of body motion via appropriate smoothing of acceleration data. Aquat. Biol. 4, 235-241.

Tanaka H., Takagi T., Naito Y., 2001. Swimming speeds and buoyancy compensation of migrating adult chum salmon Oncorhynchus keta revealed by speed/depth/acceleration data logger. J. Exp. Biol. 202, 3895-3904. 
Titterton D.H., 2005. Strapdown Inertial Navigation Technology. Peter Peregrinus Ltd. Institution of Electrical Engineers.

Trawny N., Roumeliotis S.I., 2005. Indirect Kalman filter for 3D attitude estimation. University of Minnesota, Dept. of Comp. Sci. \& Eng., Tech. Rep. 2.

Tsuda Y., Kawabe R., Tanaka H., Mitsunaga Y., Hiraishi T., Yamamoto K., Nashimoto K., 2006. Monitoring the spawning behaviour of chum salmon with an acceleration data logger. Ecol. Freshw. Fish. 15, 264-274.

Whitney N.M., Pratt H.L.Jr., Pratt T.C., 2010. Identifying shark mating behaviour using three-dimensional acceleration loggers. Endanger Species Res. 10, 71-82.

Wilson R.P., Shepard E.L.C., Liebsch N., 2008. Prying into the intimate details of animal lives: use of a daily diary on animals. Endanger Species Res. 4, 123-137.

Wilson R.P, White C.R., Quintana F., Halsey L.G., Liebsch N., Martin G.R., Butler P.J., 2006. Moving towards acceleration for estimates of activityspecific metabolic rate in free-living animals: the case of the cormorant. J. Anim. Ecol. 75, 1081-1090. 


\section{Figure Legends}

\section{Figure 1}

Diagram demonstrating the extraction of angular and time-distance variables from the gyro logger measurements. An orientation filter (Madgwick et al., 2011) was implemented to integrate the gyro logger measurements.

\section{Figure 2}

Four coordinate frames were assumed; the earth frame $\left(\mathrm{X}_{E}, \mathrm{Y}_{E}, \mathrm{Z}_{E}\right)$, camera frame $\left(\mathrm{X}_{C}, \mathrm{Y}_{C}, \mathrm{Z}_{C}\right)$, fish frame $\left(\mathrm{X}_{F}, \mathrm{Y}_{F}, \mathrm{Z}_{F}\right)$, and data logger frame $\left(\mathrm{X}_{L}\right.$, $\left.\mathrm{Y}_{L}, \mathrm{Z}_{L}\right)$

\section{Figure 3}

a) Angular velocity in the z-direction (turning rate), as obtained from the gyroscope measurements, and b) the calculated yaw angle, which shows the $\mathrm{S} 1$ and S2 durations and angles.

\section{Figure 4}

A typical profile of the comparison of a) cumulative distance, velocity, acceleration, turning rate and turning angle (yaw angle), and b) 2D trajectory for a fixed duration of 0.18 between the gyro logger measurements (solid line) and the camera recordings (dashed line) during an escape event.

\section{Figure 5}

Regression analysis of the locomotor variables estimated from the gyro logger (x-axis) and from the camera recordings (y-axis) showing a linear regression 
line (solid line) and the lower and upper $95 \%$ confidence interval (dotted line). The locomotor variables examined included (a) cumulative distance: Video $=1.08 \times$ Logger $+0.02 ; R^{2}=0.85 ; \mathrm{F}$ value $=128.60(1$ and 22 Degree of Freedom (D.F.)); $\mathrm{p}<0.0001 ; \mathrm{N}=24$, (b) maximum velocity: Video $=$ $0.85 \times$ Logger $+0.21 ; R^{2}=0.56 ; \mathrm{F}$ value $=28.47(1$ and 22 D.F. $) ; \mathrm{p}<$ $0.0001 ; \mathrm{N}=24$, (c) maximum acceleration: $R^{2}=0.01 ; \mathrm{F}$ value $=0.13(1$ and 22 D.F.); $\mathrm{p}=0.73 ; \mathrm{N}=24$, (d) turning rate: Video $=0.78 \times$ Logger $+102.98 ; R^{2}=0.53 ; \mathrm{F}$ value $=22.36(1$ and 20 D.F. $) ; \mathrm{p}<0.001 ; \mathrm{N}=22$, (e) $\mathrm{S} 1$ angle: Video $=0.95 \times$ Logger $+6.86 ; R^{2}=0.41 ; \mathrm{F}$ value $=13.95$ (1 and 20 D.F.); $\mathrm{p}<0.01 ; \mathrm{N}=22$, (f) S2 angle: Video $=0.97 \times$ Logger $2.20 ; R^{2}=0.93 ; \mathrm{F}$ value $=108.6(1$ and 8 D.F. $) ; \mathrm{p}<0.0001 ; \mathrm{N}=10,(\mathrm{~g})$ $\mathrm{S} 1$ duration: Video $=1.02 \times$ Logger $-0.00 ; R^{2}=0.99 ; \mathrm{F}$ value $=2785(1$ and 20 D.F.); $\mathrm{p}<0.0001 ; \mathrm{N}=24$, and (h) S2 duration: Video $=0.98 \times$ Logger $+0.00 ; R^{2}=0.97 ; \mathrm{F}$ value $=263.2(1$ and 8 D.F. $) ; \mathrm{p}<0.0001 ; \mathrm{N}=10$.

\section{Figure 6}

Typical profile of locomotor variables in a single- (solid line) and double-bend (dashed line) escape movement.Timing difference of maximum acceleration along the $\mathrm{x}$ - and $\mathrm{y}$-axes are also shown. Turning rate corresponds to the angular velocity in the z-direction.

\section{Figure 7}

Box plot showing the difference in the timing of maximum acceleration along the $\mathrm{x}$ - and $\mathrm{y}$-axes for the two types of escape movements (single-bend; $\mathrm{N}$ $=11$, double-bend; $\mathrm{N}=13$ ). The timing difference indicates the difference 
902

904

905

906

in the time required to reach maximum acceleration between the $\mathrm{x}$ - and $\mathrm{y}$ positions $\left(T_{x}-T_{y}\right)$.

\section{Figure 8}

Variation in the ODBA (mean \pm s.e.m.) for different running-mean durations for smoothing $(\mathrm{N}=41)$. The acceleration is presented in $g$ units as previously described (Shepard et al., 2008).

\section{Figure 9}

Example of raw accelerometer measurements (gray line) and gravity-based accelerations determined using the gyro (black line) or the smoothing method with a running mean duration of $0.1 \mathrm{~s}$ (dotted black line) or $0.3 \mathrm{~s}$ (dotted gray line) in the $\mathrm{x}-, \mathrm{y}$ - and z-directions. Although the acceleration in escape events is usually higher than $\pm 1 \mathrm{~g}$, accelerations within the range of $-1 \sim 1 \mathrm{~g}$ are displayed. 
${ }_{918}$ Tables 
Table 1: Summary of the mean (s.e.m.) values of the locomotor variables in escape movements (single- and double-bend responses). The significant differences between the variables for the two types of escape movements $(\mathrm{N}=24)$ are also shown.

\begin{tabular}{|c|c|c|c|c|c|c|}
\hline & single-bend & double-bend & all & \multicolumn{3}{|c|}{ RM-ANOVA } \\
\hline variable & mean (s.e.m.) & mean (s.e.m.) & mean (s.e.m.) & df & F value & $\mathrm{p}$ \\
\hline$A_{\max }$ in $\mathrm{x}\left(\mathrm{m} \mathrm{s}^{-2}\right)^{\mathrm{a}}$ & $82.73(4.54)$ & $106.38(6.62)$ & $93.57(4.59)$ & 1 & 8.34 & $<0.01 * *$ \\
\hline$A_{\max }$ in $\mathrm{y}\left(\mathrm{m} \mathrm{s}^{-2}\right)$ & $37.09(3.29)$ & $62.31(4.71)$ & $48.65(3.80)$ & 1 & 18.50 & $<0.001 * * *$ \\
\hline$A_{\max }$ in $\mathrm{z}\left(\mathrm{m} \mathrm{s}^{-2}\right)$ & $55.57(4.81)$ & $83.85(4.41)$ & $68.53(4.37)$ & 1 & 17.67 & $<0.001 * * *$ \\
\hline$M A_{\max }\left(\mathrm{m} \mathrm{s}^{-2}\right)^{\mathrm{b}}$ & $85.87(4.50)$ & $121.25(7.11)$ & $102.09(5.43)$ & 1 & 17.18 & $<0.001 * * *$ \\
\hline$M V_{\max }\left(\mathrm{m} \mathrm{s}^{-1}\right)^{\mathrm{c}}$ & $1.27(0.08)$ & $1.52(0.08)$ & $1.38(0.06)$ & 1 & 4.21 & 0.05 \\
\hline Cum Dist $\left(\mathrm{m} \mathrm{s}^{-1}\right)^{\mathrm{d}}$ & $0.11(0.01)$ & $0.17(0.01)$ & $0.14(0.01)$ & 1 & 16.95 & $<0.001 * * *$ \\
\hline$\omega_{\max }$ in $\mathrm{x}\left(\operatorname{deg~s}^{-1}\right)^{\mathrm{e}}$ & $369.04(45.76)$ & $708.13(58.14)$ & $524.46(50.14)$ & 1 & 30.07 & $<0.001 * * *$ \\
\hline$\omega_{\max }$ in $\mathrm{y}\left(\operatorname{deg} \mathrm{s}^{-1}\right)$ & $1047.36(81.37)$ & $1759.25(79.71)$ & $1373.64(92.30)$ & 1 & 36.36 & $<0.001 * * *$ \\
\hline$\omega_{\max }$ in $\mathrm{z}\left(\operatorname{deg} \mathrm{s}^{-1}\right)$ & $796.23(48.28)$ & $844.62(52.48)$ & $818.41(35.87)$ & 1 & 2.62 & 0.12 \\
\hline S1 angle (deg) & $45.27(2.60)$ & $33.91(3.42)$ & $40.06(2.37)$ & 1 & 7.23 & $<0.05^{*}$ \\
\hline range of pitch (deg) & $33.74(4.02)$ & $28.01(2.09)$ & $31.11(2.45)$ & 1 & 0.20 & 0.66 \\
\hline range of roll (deg) & $23.54(2.21)$ & $24.49(1.88)$ & $23.97(1.48)$ & 1 & 0.03 & 0.86 \\
\hline S1 duration (ms) & $175.23(23.25)$ & $92.18(7.28)$ & $137.17(15.42)$ & 1 & 10.02 & $<0.01 * *$ \\
\hline$T_{y}-T_{x}(\mathrm{~ms})^{\mathrm{f}}$ & $37.69(3.76)$ & $-11.64(2.40)$ & $15.08(5.53)$ & 1 & 116.07 & $<0.001 * * *$ \\
\hline$T_{z}-T_{x}(\mathrm{~ms})^{\mathrm{g}}$ & $3.23(5.38)$ & $-5.27(6.76)$ & $-0.67(4.34)$ & 1 & 1.45 & 0.24 \\
\hline time to $M A_{\max }(\mathrm{ms})$ & $16.62(4.69)$ & $50.00(6.97)$ & $31.92(5.31)$ & 1 & 16.26 & $<0.001 * * *$ \\
\hline time to $M V_{\max }(\mathrm{ms})$ & $38.77(2.55)$ & $82.91(18.06)$ & $59.00(9.52)$ & 1 & 6.66 & $<0.05^{*}$ \\
\hline
\end{tabular}

a $A_{\max }$ refers to maximum acceleration

${ }^{b}$ maximum value of the magnitude of acceleration

${ }^{\mathrm{c}}$ maximum value of the magnitude of velocity

${ }^{\mathrm{d}}$ cumulative distance

e $\omega_{\max }$ refers to maximum angular velocity

f timing difference in $A_{\max }$ between $\mathrm{x}$ and $\mathrm{y}$

$\mathrm{g}$ timing difference in $A_{\max }$ betweent and $\mathrm{z}$ 
Table 2: Percent change [mean (s.e.m.; standard error of mean)] in the maximum, mean, s.d., and RMS of the dynamic acceleration, the ODBA, and the time required to reach maximum dynamic acceleration for different running-mean durations of smoothing as obtained from escape events $(\mathrm{N}=41)$. The values from the smoothing procedure were compared with those obtained using the gyro method.

\begin{tabular}{|c|c|c|c|c|c|c|c|c|c|c|c|c|c|c|c|c|}
\hline \multirow[b]{2}{*}{ duration (s) } & \multicolumn{3}{|c|}{ max acceleation } & \multicolumn{3}{|c|}{ mean acceleration } & \multicolumn{3}{|c|}{ s.d. of acceleration } & \multicolumn{3}{|c|}{ RMS } & \multirow{2}{*}{\begin{tabular}{|l|} 
ODBA \\
$\mathrm{x}$ \\
\end{tabular}} & \multicolumn{3}{|c|}{ time to max acceleration } \\
\hline & $\mathrm{x}$ & $\mathrm{y}$ & $\mathrm{z}$ & $\mathrm{x}$ & $\mathrm{y}$ & $\mathrm{z}$ & $\mathrm{x}$ & $\mathrm{y}$ & $\mathrm{z}$ & $\mathrm{x}$ & $\mathrm{y}$ & $\mathrm{z}$ & & $\mathrm{y}$ & $\mathrm{z}$ & \\
\hline 0.10 & $-8.53(1.04)$ & $-17.44(2.25)$ & $-1.11(1.32)$ & $-103.96(4.22)$ & $-99.76(0.25)$ & $-105.31(5.66)$ & $-7.72(1.01)$ & $-20.35(1.72)$ & $-0.21(0.92)$ & $-8.10(1.05)$ & $-21.78(1.75)$ & $-0.32(0.93)$ & $-10.53(1.24)$ & $-0.29(0.17)$ & $-0.53(0.39)$ & $-0.30(0.14)$ \\
\hline 0.20 & $-1.75(0.77)$ & $-11.38(1.47)$ & $2.62(0.60)$ & $-99.46(0.39)$ & $-109.89(10.31)$ & $0.47(0.62)$ & $-10.90(0.93)$ & $4.13(0.56)$ & $0.03(0.57)$ & $-12.52(1.00)$ & $4.01(0.57)$ & $1.47(1.05)$ & $0.05(0.25)$ & $-0.37(0.40)$ & $-0.29(0.14)$ & $-115.55(9.86)$ \\
\hline 0.30 & $-1.31(0.56)$ & $-8.15(1.28)$ & $2.19(0.42)$ & $-129.26(17.04)$ & $-99.17(0.60)$ & $-107.14(8.37)$ & $0.30(0.36)$ & $-6.63(0.61)$ & $2.61(0.31)$ & $-0.13(0.38)$ & $-8.34(0.70)$ & $2.49(0.31)$ & $4.27(0.81)$ & $0.05(0.28)$ & $-0.36(0.39)$ & $-0.08(0.08)$ \\
\hline 0.40 & $-1.07(0.48)$ & $-6.49(1.12)$ & $2.33(0.40)$ & $-138.37(23.11)$ & $-98.87(0.84)$ & $-105.10(7.01)$ & $0.55(0.28)$ & $-4.07(0.58)$ & $2.93(0.28)$ & $0.12(0.29)$ & $-5.83(0.65)$ & $2.82(0.28)$ & $6.72(0.76)$ & $-0.19(0.13)$ & $-0.27(0.39)$ & $-0.08(0.08)$ \\
\hline 0.50 & $-0.64(0.40)$ & $-5.01(0.99)$ & $2.40(0.38)$ & $-149.89(31.02)$ & $-98.38(1.07)$ & $-101.41(6.23)$ & $0.87(0.30)$ & $-2.05(0.66)$ & $3.06(0.26)$ & $0.43(0.30)$ & $-3.86(0.69)$ & $2.94(0.26)$ & $8.73(0.75)$ & $-0.08(0.08)$ & $0.20(0.14)$ & $-0.08(0.08)$ \\
\hline 0.60 & $-0.46(0.37)$ & $-3.96(0.90)$ & $2.40(0.35)$ & $-165.43(43.39)$ & $-97.55(1.26)$ & $-97.16(9.59)$ & $1.12(0.32)$ & $-0.75(0.71)$ & $3.08(0.25)$ & $0.69(0.32)$ & $-2.59(0.73)$ & $2.97(0.25)$ & $10.14(0.73)$ & $-0.08(0.08)$ & $0.20(0.14)$ & $-0.08(0.08)$ \\
\hline
\end{tabular}


Table A1: Summary of the total (TL) and fork (FL) lengths, body mass (BM), and number of observed escape $\left(\mathrm{N}_{e}\right)$ activities identified using the video images for 5 (A-E) different Japanese amberjacks. The $\mathrm{N}_{e}$ number in parentheses indicates the number of escape responses that were simultaneously recorded with a high-speed camera.

\begin{tabular}{|l|l|l|l|l|}
\hline fish ID & TL $(\mathbf{c m})$ & FL $(\mathbf{c m})$ & BM $(\mathbf{k g})$ & $\mathbf{N}_{\mathbf{e}}$ \\
\hline A & 71.6 & 66.8 & 3.2 & $11(4)$ \\
\hline B & 66.6 & 60.9 & 4.1 & $8(5)$ \\
\hline C & 69.8 & 63.9 & 3.8 & $11(8)$ \\
\hline D & 77.8 & 73.1 & 5.3 & $4(3)$ \\
\hline E & 67.8 & 65.0 & 3.9 & $7(4)$ \\
\hline & & & total & $41(24)$ \\
\hline
\end{tabular}


${ }_{919}$ Figures 




Time-distance variables

Figure 1: Diagram demonstrating the extraction of angular and time-distance variables from the gyro logger measurements. An orientation filter (Madgwick et al., 2011) was implemented to integrate the gyro logger measurements. 


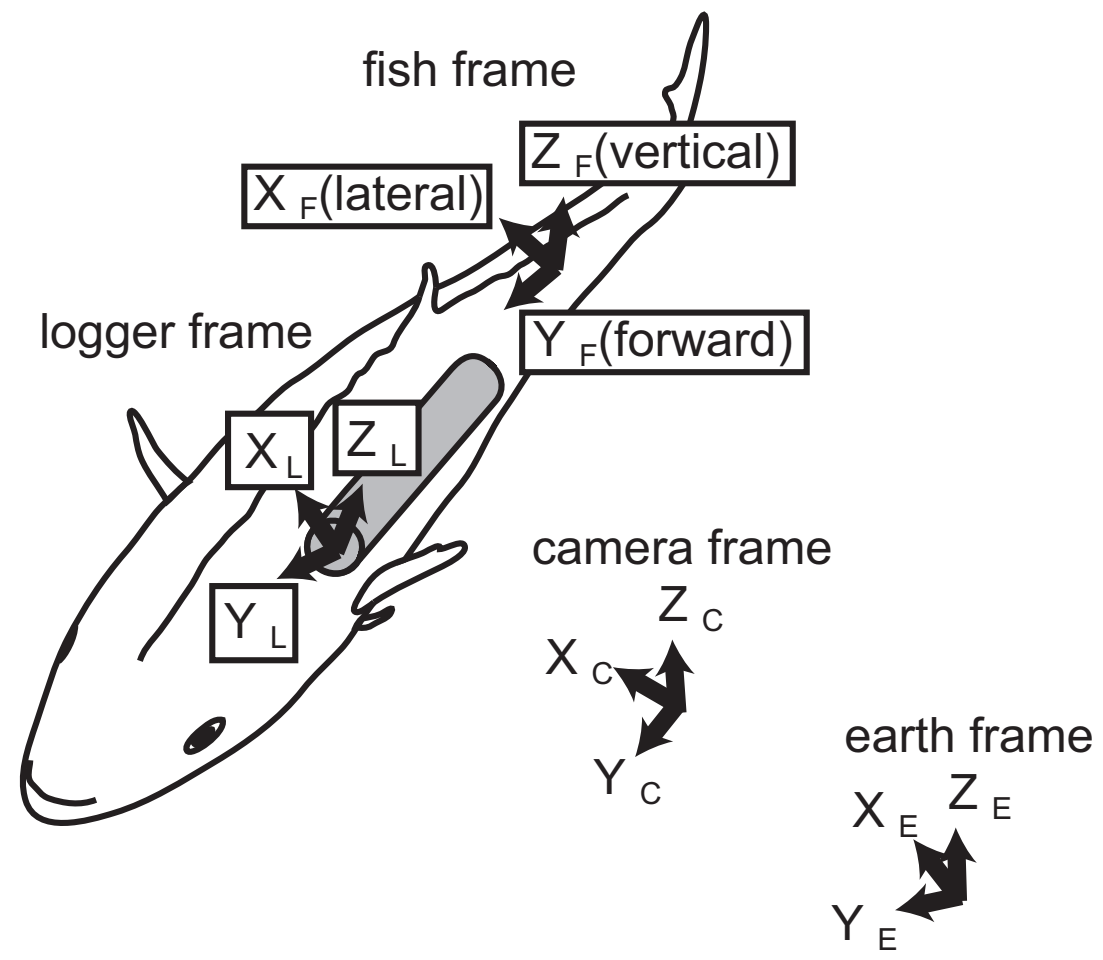

Figure 2: Four coordinate frames were assumed; the earth frame $\left(\mathrm{X}_{E}, \mathrm{Y}_{E}, \mathrm{Z}_{E}\right)$, camera frame $\left(\mathrm{X}_{C}, \mathrm{Y}_{C}, \mathrm{Z}_{C}\right)$, fish frame $\left(\mathrm{X}_{F}, \mathrm{Y}_{F}, \mathrm{Z}_{F}\right)$, and data logger frame $\left(\mathrm{X}_{L}, \mathrm{Y}_{L}, \mathrm{Z}_{L}\right)$.
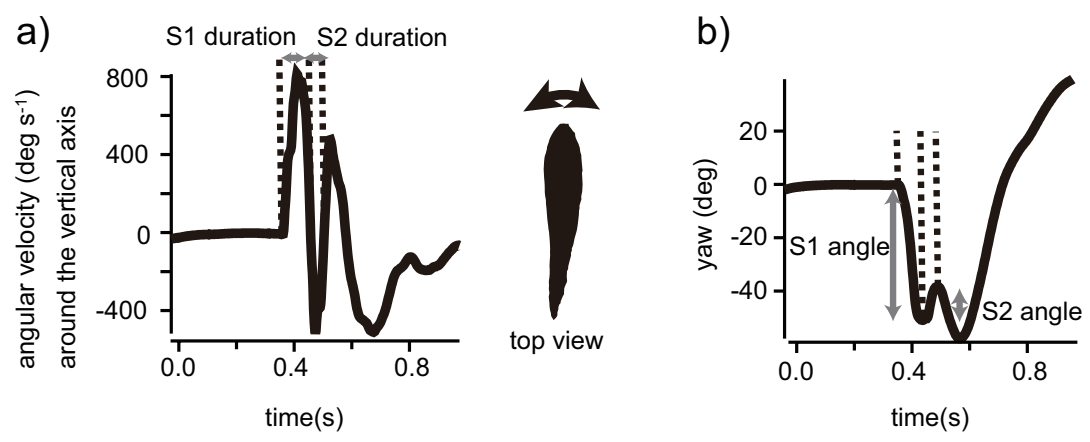

Figure 3: a) Angular velocity in the z-direction (turning rate), as obtained from the gyroscope measurements, and b) the calculated yaw angle, which shows the S1 and S2 durations and angles. 

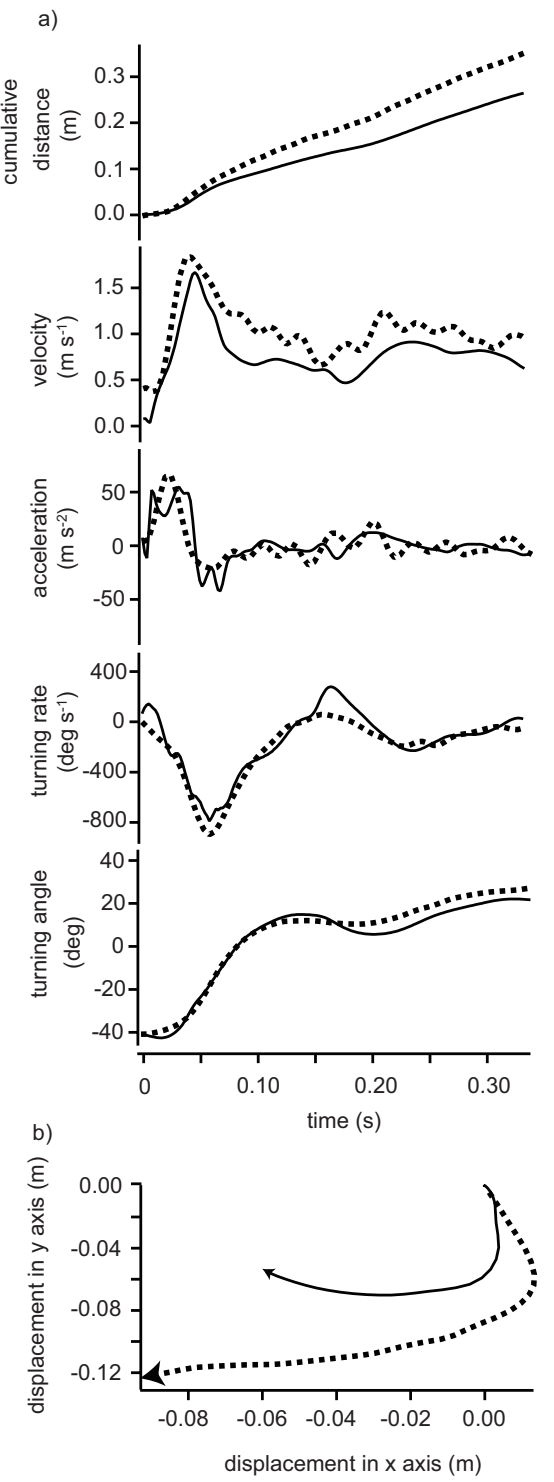

Figure 4: A typical profile of the comparison of a) cumulative distance, velocity, acceleration, turning rate and turning angle (yaw angle), and b) 2D trajectory for a fixed duration of 0.18 between the gyro logger measurements (solid line) and the camera recordings (dashed line) during an escape event. 

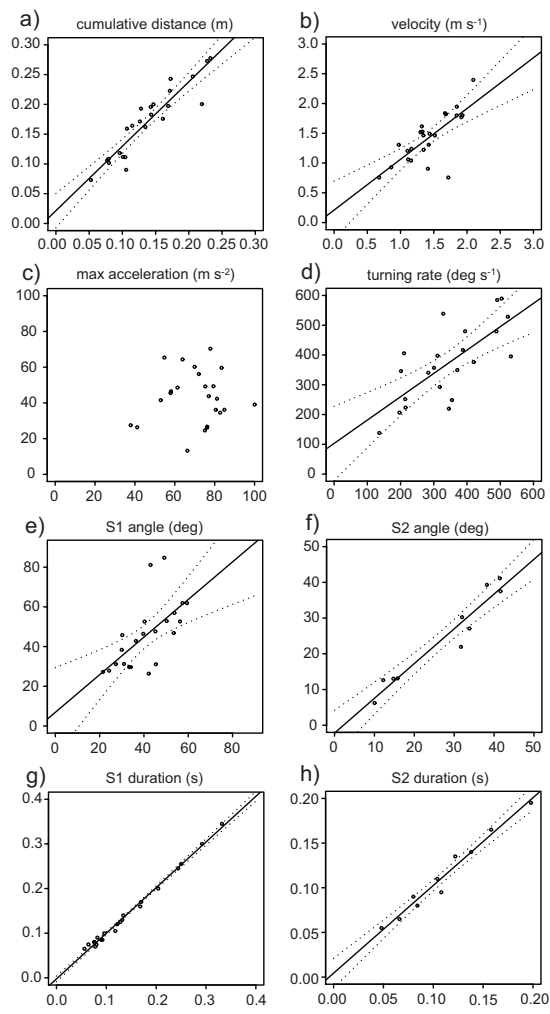

Figure 5: Regression analysis of the locomotor variables estimated from the gyro logger (xaxis) and from the camera recordings (y-axis) showing a linear regression line (solid line) and the lower and upper $95 \%$ confidence interval (dotted line). The locomotor variables examined included (a) cumulative distance: Video $=1.08 \times$ Logger $+0.02 ; R^{2}=0.85 ; \mathrm{F}$ value $=128.60(1$ and 22 Degree of Freedom (D.F.)); $<<0.0001 ; \mathrm{N}=24$, (b) maximum velocity: Video $=0.85 \times$ Logger $+0.21 ; R^{2}=0.56 ; \mathrm{F}$ value $=28.47(1$ and 22 D.F. $) ; \mathrm{p}$ $<0.0001 ; \mathrm{N}=24$, (c) maximum acceleration: $R^{2}=0.01 ; \mathrm{F}$ value $=0.13$ (1 and 22 D.F.); $\mathrm{p}=0.73 ; \mathrm{N}=24,(\mathrm{~d})$ turning rate: Video $=0.78 \times$ Logger $+102.98 ; R^{2}=0.53 ; \mathrm{F}$ value $=22.36$ ( 1 and 20 D.F.); p < 0.001; $\mathrm{N}=22$, (e) S1 angle: Video $=0.95 \times$ Logger +6.86 ; $R^{2}=0.41 ; \mathrm{F}$ value $=13.95(1$ and 20 D.F. $) ; \mathrm{p}<0.01 ; \mathrm{N}=22$, (f) S2 angle: Video $=0.97$ $\times$ Logger $-2.20 ; R^{2}=0.93 ; \mathrm{F}$ value $=108.6(1$ and 8 D.F. $) ; \mathrm{p}<0.0001 ; \mathrm{N}=10,(\mathrm{~g}) \mathrm{S} 1$ duration: Video $=1.02 \times$ Logger $-0.00 ; R^{2}=0.99 ; \mathrm{F}$ value $=2785(1$ and 20 D.F. $) ; \mathrm{p}<$ $0.0001 ; \mathrm{N}=24$, and $(\mathrm{h}) \mathrm{S} 2$ duration: Video $=0.98 \times$ Logger $+0.00 ; R^{2}=0.97 ; \mathrm{F}$ value $=263.2(1$ and 8 D.F. $) ; \mathrm{p}<0.0001 ; \mathrm{N}=10$. 

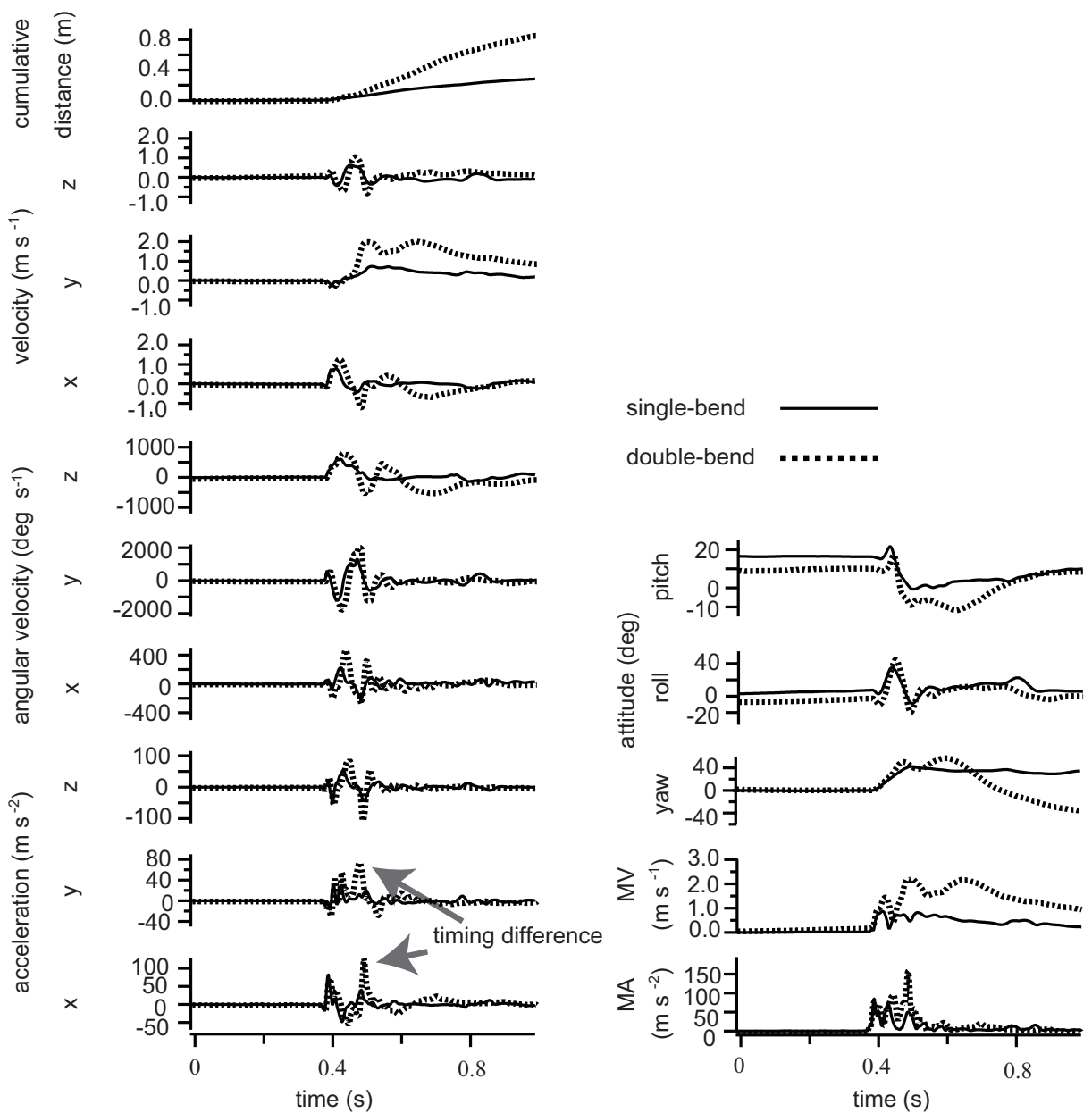

Figure 6: Typical profile of locomotor variables in a single- (solid line) and double-bend (dashed line) escape movement.Timing difference of maximum acceleration along the $\mathrm{x}$ and y-axes are also shown. Turning rate corresponds to the angular velocity in the zdirection. 


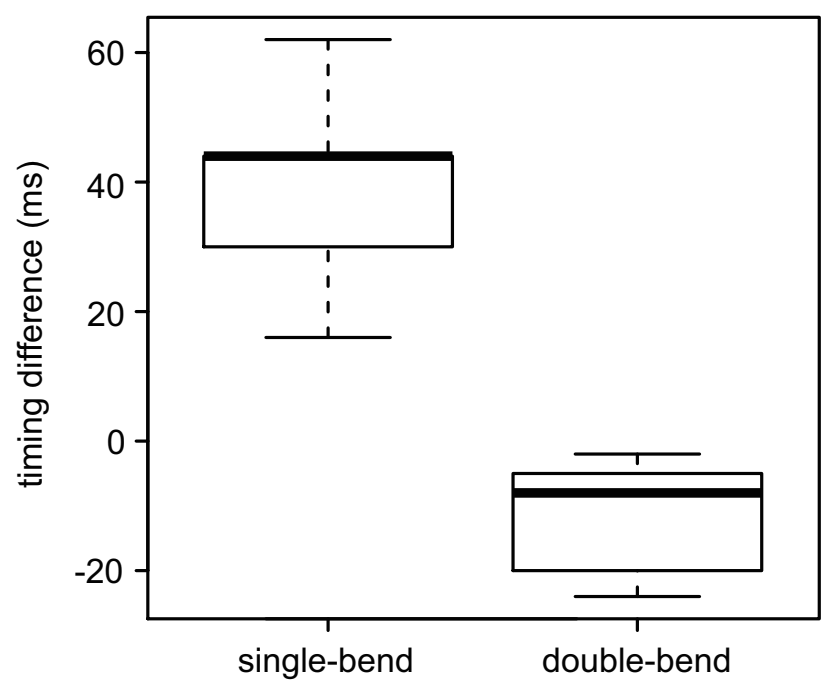

Figure 7: Box plot showing the difference in the timing of maximum acceleration along the $\mathrm{x}$ - and $\mathrm{y}$-axes for the two types of escape movements (single-bend; $\mathrm{N}=11$, doublebend; $\mathrm{N}=13$ ). The timing difference indicates the difference in the time required to reach maximum acceleration between the $\mathrm{x}$ - and y-positions $\left(T_{x}-T_{y}\right)$. 


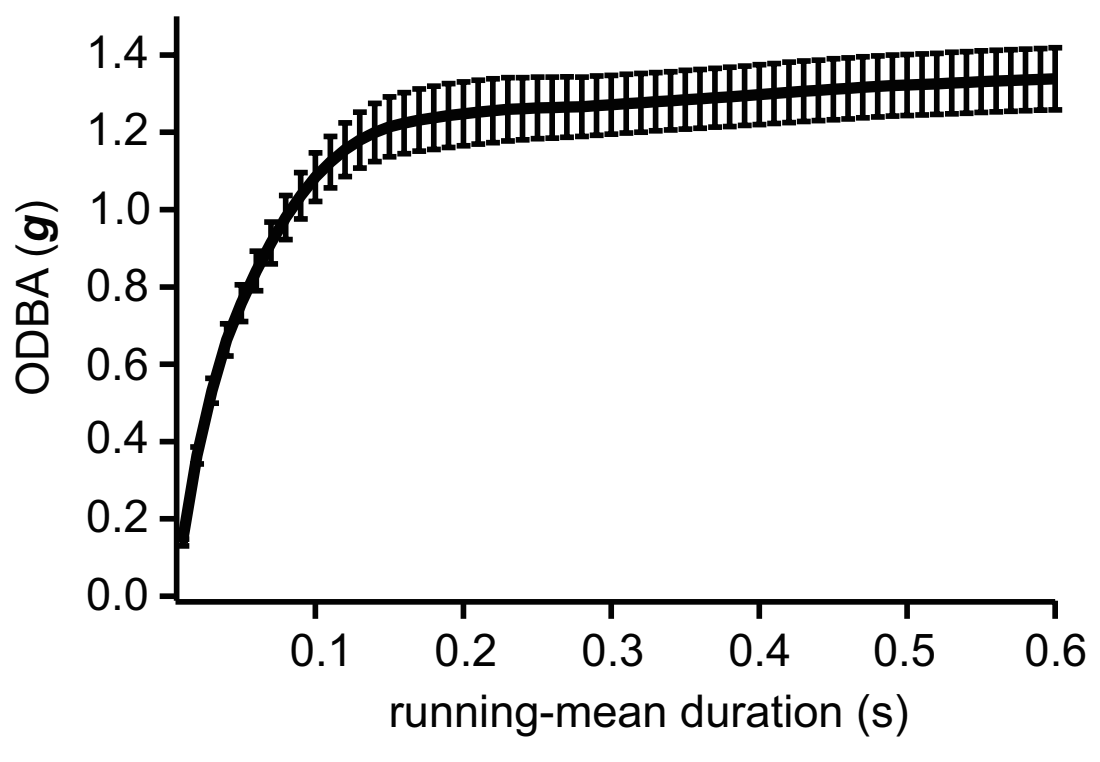

Figure 8: Variation in the ODBA (mean \pm s.e.m.) for different running-mean durations for smoothing $(\mathrm{N}=41)$. The acceleration is presented in $g$ units as previously described (Shepard et al., 2008). 

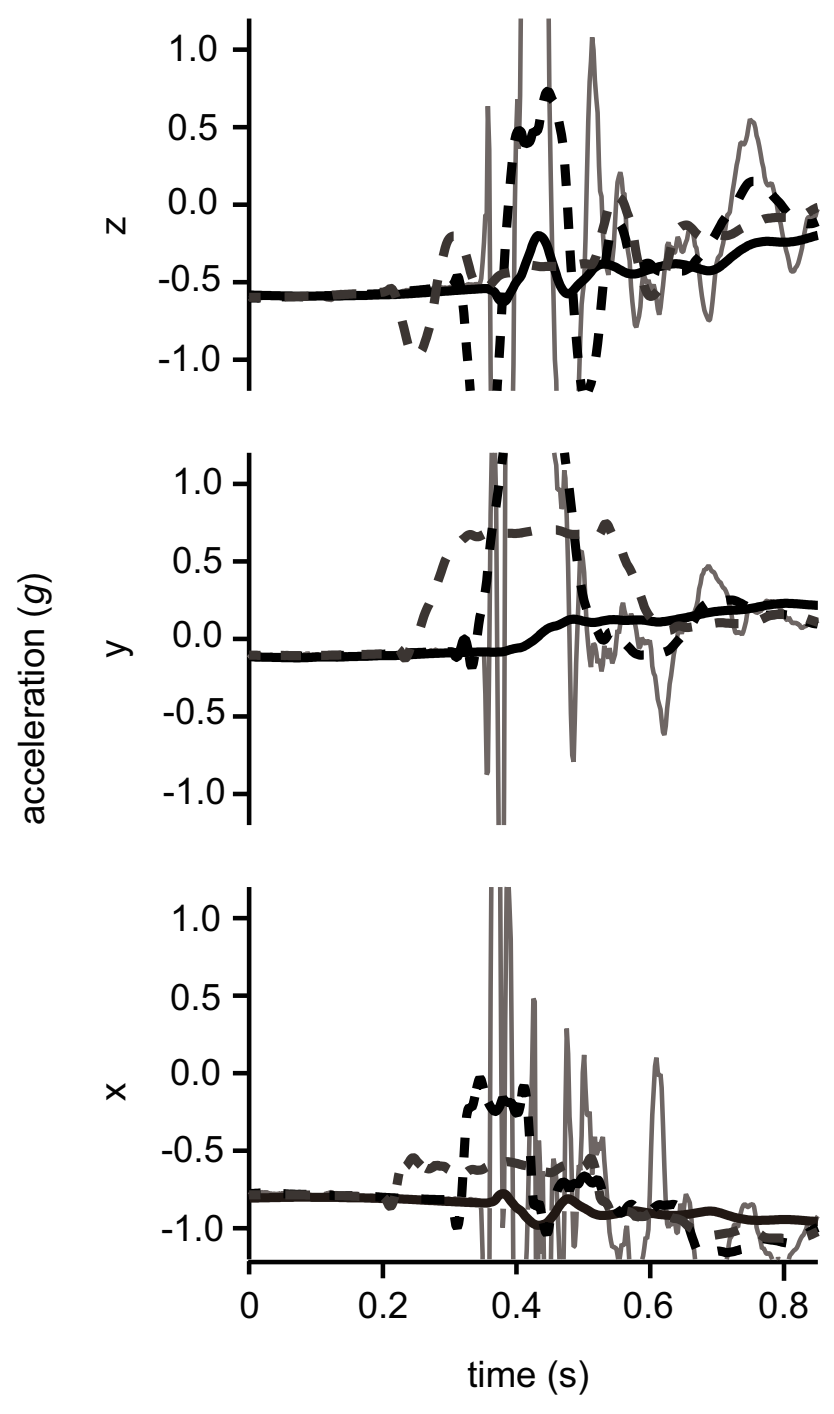

Figure 9: Example of raw accelerometer measurements (gray line) and gravity-based accelerations determined using the gyro (black line) or the smoothing method with a running mean duration of $0.1 \mathrm{~s}$ (dotted black line) or $0.3 \mathrm{~s}$ (dotted gray line) in the $\mathrm{x}-, \mathrm{y}-$ and z-directions. Although the acceleration in escape events is usually higher than $\pm 1 g$, accelerations within the range of $-1 \sim 1 \mathrm{~g}$ are displayed. 
a)

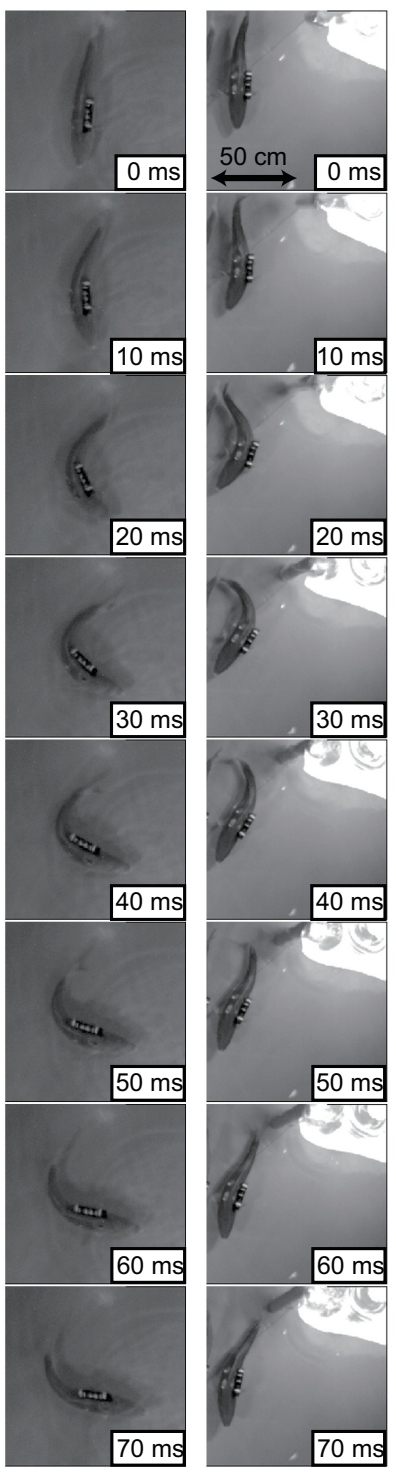

Figure A1: Image sequences of a) single- and b) double-bend escape movements. 